\title{
Histological demonstration of copper and copper-associated protein in chronic liver diseases
}

\author{
S. JAIN, P. J. SCHEUER, BARBARA ARCHER, S. P. NEWMAN, \\ AND SHEILA SHERLOCK
}

From the Departments of Medicine, Histopathology, and Physics, Royal Free Hospital, Pond Street, London NW3 2QG, UK

SUMMARY Liver copper concentrations in percutaneous biopsy specimens were measured by neutron activation analysis and compared with histological staining for copper by rubeanic acid and rhodanine, and with copper-associated protein stained by orcein. Liver copper concentrations were elevated in 31 of 35 biopsies from patients with primary biliary cirrhosis (PBC), and discrimination between normal and elevated liver copper was correct in 32 of the 35 biopsies by staining with rubeanic acid, and in 31 of the 35 by staining with rhodanine. Orcein staining of copper-associated protein was positive in 33 of the 35 biopsies. All 17 biopsy specimens from patients with Wilson's disease had high liver copper concentrations, but only nine had positive staining for copper, and six were orcein positive. Similarly, histological stains gave little indication of the liver copper concentrations in tissue from 16 patients with chronic active hepatitis. Staining of liver sections can be useful in detecting elevation of liver copper in PBC, but not in Wilson's disease, where the absolute concentration must be measured. Excess copper appears to accumulate in the liver in different chemical forms in PBC and Wilson's disease.

Hepatic copper concentration is high in patients with Wilson's disease (Cumings, 1948) and is responsible for the liver damage (Sternlieb, 1972). Patients with the untreated disease usually have liver copper concentrations above $4.0 \mathrm{mmol} / \mathrm{kg}$ of dry liver, normal range 0.25-0.90 mmol/kg (Sternlieb and Scheinberg, 1968). Approximately $80 \%$ of absorbed copper is normally excreted in bile and lost in the faeces (Cartwright and Wintrobe, 1964), and the cholestasis of primary biliary cirrhosis (PBC) and long-standing extrahepatic biliary obstruction can cause elevation of liver copper concentrations above $4.0 \mathrm{mmol} / \mathrm{kg}$ (Hunt et al., 1963; Smallwood et al., 1968). Some patients with chronic active hepatitis (CAH) and alcoholic cirrhosis also have raised liver copper concentrations, but not to the levels found in Wilson's disease and PBC (Smallwood et al., 1968; Fleming et al., 1974).

Cytoplasmic material, which stains with orcein, has been found in the same cellular and subcellular locations as stainable copper in liver biopsy specimens from patients with prolonged cholestasis.

Received for publication 12 January 1978
This suggests that copper is retained in copperprotein complexes in the cytoplasm (Salaspuro and Sipponen, 1976; Sipponen, 1976) as a result of cholestasis of any cause.

In order to evaluate different methods of demonstrating excess copper in patients with chronic liver disease, we have compared the results of liver copper measurement by neutron activation analysis with copper staining by rubeanic acid and rhodanine, and with staining of copper-associated protein by the orcein method.

\section{Material and methods}

NEUTRON ACTIVATION ANALYSIS (NAA)

Percutaneous liver biopsies were performed with Menghini needles, which were prepared by washing in a $1 \%$ solution of ethylene-diamine-tetra-acetic acid (EDTA) to remove surface copper. A sample of each biopsy was separated, freeze-dried, weighed, and submitted for NAA by the technique of Todd et al. (1967).

HISTOLOGICAL STAINING METHODS

Paraffin sections of liver biopsy specimens, 4-5 784 
microns, were fixed in neutral buffered formolsaline. The sections were stained with rubeanic acid (Cook,1974), with reagent supplied by Raymond A. Lamb, London, using the staining solution at room temperature for 24 hours, and with rhodanine (BDH Chemicals Ltd) by the method of Lindquist (1969). The sections were also stained by Shikata's orcein method (BDH Chemicals Ltd), using a modified oxidising solution (Deodhar et al., 1975). This stains sulphonic acid residues formed from sulphydryl groups during oxidation, including hepatitis B surface antigen $\left(\mathrm{HB}_{\mathrm{s}} \mathrm{Ag}\right)$ (Shikata et al., 1974), a copper-associated protein (Salaspuro and Sipponen, 1976), and elastic fibres.

Each slide was examined by one observer (PJS) without knowledge of the liver copper concentration of the biopsy specimen, and the degree of staining by each of the three methods was scored 0 to 3 , where 0 was negative, 1 minimal, 2 positive, and 3 heavy staining (Fig. 1). Both extent and density of staining were taken into account.

\section{Evaluation of methods}

\section{NEUTRON ACTIVATION ANALYSIS}

The reproducibility of the technique was tested by measuring the copper concentration of differing weights of a powder made up of glucose and copper sulphate, with a copper concentration of approximately $3 \mathrm{mmol} / \mathrm{kg}$. The weights of the samples submitted for analysis ranged from 1 to $10 \mathrm{mg}$. The coefficient of variation in 15 samples was $12.4 \%$.
The sampling error of copper measurement in cirrhotic livers was assessed by taking multiple cores with a Menghini needle from a cirrhotic liver obtained at necropsy. The coefficients of variation of the liver copper concentrations ranged from $36.1 \%$, when portions of less than $1 \mathrm{mg}$ dry weight were compared, to $4.0 \%$ on samples weighing $3-5 \mathrm{mg}$. These results show that, provided more than $3 \mathrm{mg}$ of liver (10 $\mathrm{mg}$ wet weight) is used, sampling error is unlikely to be important as the variation is within that of the measuring technique. These results are similar to those of Fleming et al. (1974), using atomic absorption spectrophotometry.

\section{HISTOLOGICAL STAINING METHODS}

In order to evaluate the three methods used for copper and copper-associated protein, the effect of prior removal of copper from the sections was investigated. Sodium diethyldithiocarbamate (DTC) (Hopkin and Williams Ltd), which forms a coloured complex with copper (Howell, 1959) and which can be dissolved in alcohol, was used to remove copper from sections (Scheuer and Barka, 1963). Because removal of the coloured compound can be checked optically, this method was preferred to non-specific copper-removing procedures such as the permanganate-oxalic acid step in the orcein method (Deodhar et al., 1975). Mallory's haematoxylin method for copper (Mallory and Parker, 1939) was also used because this method is thought to rely on the presence of metallic copper to mordant the

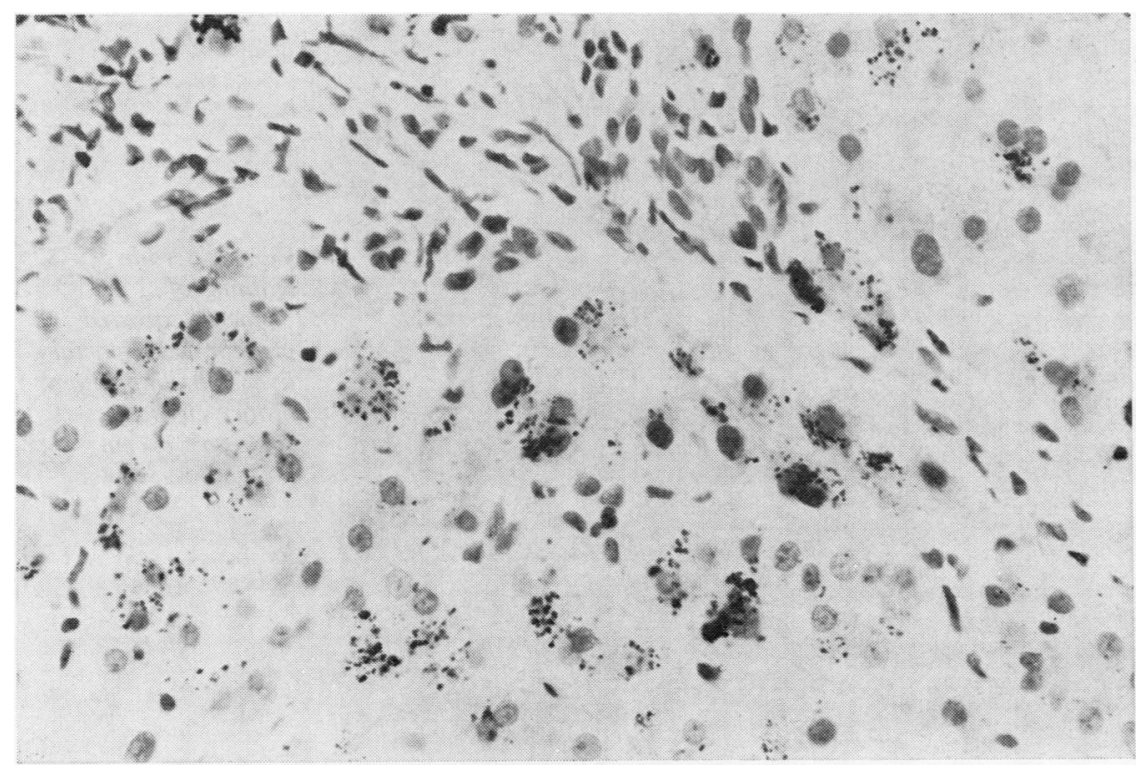

Fig. 1 Grade 3 copper staining in periportal liver cells in primary biliary cirrhosis. Rhodanine $\times 380$ 
haematoxylin, and is thus considered very specific for the method.

As shown in Table 1, staining by Mallory's haematoxylin, rhodanine, and rubeanic acid was prevented by prior removal of copper by means of DTC and alcohol. Shikata's orcein staining was not affected. This is in agreement with the conclusion of Salaspuro and Sipponen (1976), that orcein stains a copper-binding protein rather than copper itself. Problems of technique and interpretation of the different staining methods were relatively minor. There was gradual fading of rhodanine staining over a period of several days, particularly in biopsy specimens from patients with $\mathrm{PBC}$ and when copper was scanty. A similar problem was noted by Lindquist (1969), using Permount as a mounting medium for the sections. In our experiments, the degree of fading differed according to the mounting medium used. This was greatest with Eukitt, less with DPX and Diatex, and least with Ralmount (all products of Raymond A. Lamb).

Table 1 Effect of removal of copper from sections by DTC and alcohol on copper staining methods

\begin{tabular}{lllll}
\hline & \multicolumn{2}{l}{ Stain } & & \\
\cline { 2 - 5 } & $\begin{array}{l}\text { Mallory's } \\
\text { haematoxylin }\end{array}$ & Rhodanine & Rubeanic acid Shikata \\
\hline Untreated & + & + & + & + \\
Copper removed & - & - & - & + \\
\hline
\end{tabular}

There was no difficulty in distinguishing orceinpositive granules of copper-associated protein (Fig. 2) from hepatitis B surface antigen in liver-cell $\underset{\vec{c}}{\vec{P}}$ cytoplasm or elastic tissue which orcein also stained. Lipofuscin pigment was also easily distinguished from copper-associated protein, for it did not stain with orcein and was usually in a different location, being found mainly around centrilobular veins. Copper-associated protein was mainly periportal, of and was often seen in areas of piecemeal necrosis $\overrightarrow{0}$ within the cytoplasm of swollen liver cells. In some biopsy specimens, particularly those with abundant orcein-positive granules, the presence of copperassociated protein could be predicted in sections stained by other methods; the material often appeared as grey pigment granules, somewhat resembling intracellular deposits of bile, and was usually PAS positive after diastase digestion.

\section{Patients}

Liver copper concentration and staining for copper and copper-associated protein was performed on biopsy specimens from six patients who were found to have no liver disease, 35 patients with $\mathrm{PBC}$, and 17 with Wilson's disease (six were on D-penicillamine treatment). Sixteen patients with CAH were studied; eight were $\mathrm{HB}_{\mathrm{s}} \mathrm{Ag}$ positive, and eight were $\mathrm{HB}_{\mathrm{s}} \mathrm{Ag}$ negative women with clinical and serological features of 'lupoid' hepatitis receiving oral corticosteroid therapy.

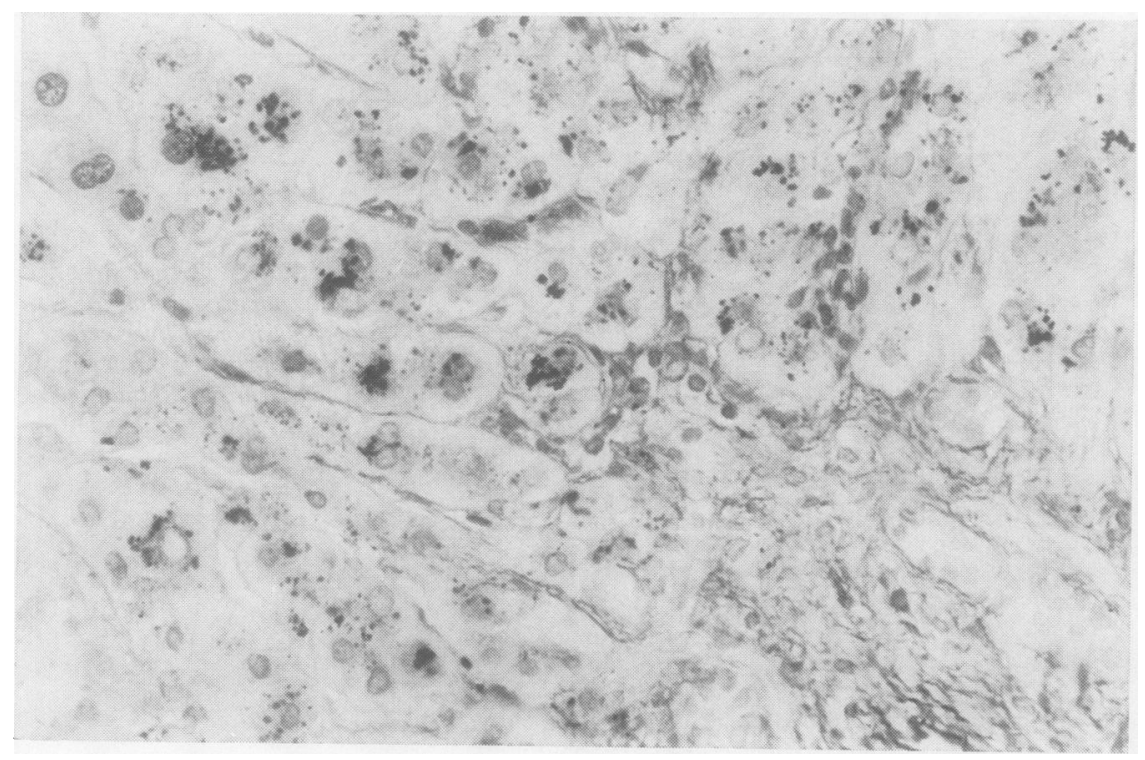

Fig. 2 Grade 3 staining of copper-associated protein in periportal liver cells in primary biliary cirrhosis. Shikata's orcein method $\times 380$ 


\section{Results}

The six histologically normal liver biopsy specimens had copper concentrations of below $0.9 \mathrm{mmol} / \mathrm{kg}$ and did not stain with rubeanic acid, rhodanine, or orcein.

\section{PBC}

Liver copper concentration measured by NAA was elevated in 31 of the 35 specimens; the range was $0.52-22.03 \mathrm{mmol} / \mathrm{kg}$ dry liver. Thirty of the 35 specimens showed positive staining for copper by rubeanic acid. One of these had a normal liver copper concentration, and two with elevated copper had negative staining, therefore discrimination between normal and elevated liver copper concentration by rubeanic acid staining was correct in 32 of the 35 biopsy specimens (Fig. 3). The grade of copper stain-

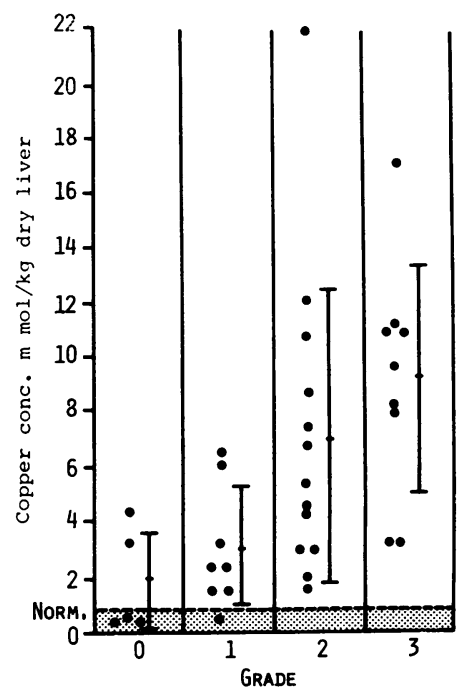

Fig. 3 Grade of staining of copper by rubeanic acid in $P B C$, compared with copper concentration in mmol/kg dry liver. Mean and SD are shown.

ing was compared with liver copper concentration, and the mean liver copper concentration rose with each grade of staining. When the liver copper concentration of each grade was compared with the others by the Mann-Whitney U ranking test, all groups differed significantly from each other at $P=0.05$ or less, except grades 1 and 2 , and 2 and 3 (Table 2). Grade 3 staining was only associated with liver copper levels above $3 \cdot 23 \mathrm{mmol} / \mathrm{kg}$.

Twenty-nine of the 35 biopsy specimens showed positive staining with rhodanine. One of these had a normal liver copper concentration, and three with
Table 2 Significance, by ranking test, of differences in liver copper concentration, in grades of copper staining by rubeanic acid

\begin{tabular}{lc}
\hline Comparison of grade & P value \\
\hline 0 and 1 & $<0.05$ \\
0 and 2 & $<0.01$ \\
0 and 3 & $<0.001$ \\
1 and 2 & NS \\
1 and 3 & $=0.001$ \\
2 and 3 & NS
\end{tabular}

NS $=$ not significant at $P=0.05$

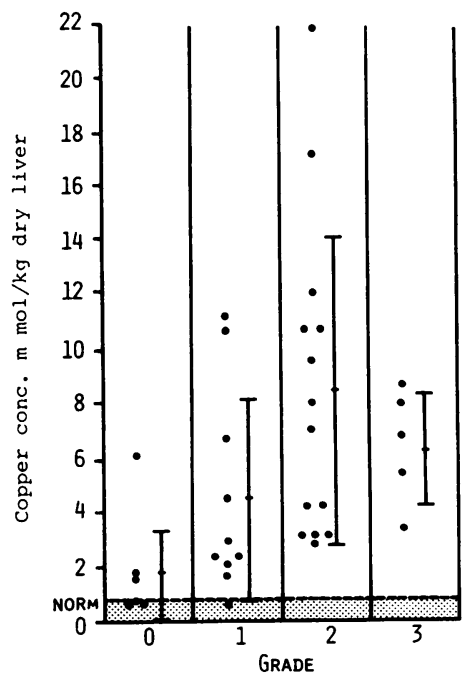

Fig. 4 Grade of staining of copper by rhodanine in $P B C$, compared with copper concentration in $\mathrm{mmol} / \mathrm{kg}$ dry liver. Mean and $S D$ are shown.

elevated liver copper had negative staining (Fig. 4), therefore discrimination between normal and elevated liver copper concentration was correct in 31 of the 35 specimens. With rhodanine there was a less clearcut relationship between liver copper concentration and the grade of staining. The mean liver copper concentration in tissue with grade 2 staining was higher than for grade 3 . The only grades which showed statistical differences of liver copper concentrations by ranking test were 0 and 2 , and 0 and 3 . Grade 2 and 3 staining was found only where the copper levels were above $3.06 \mathrm{mmol} / \mathrm{kg}$.

Rubeanic acid was slightly more sensitive than rhodanine in staining for copper in PBC. Fourteen of the 35 biopsy specimens had the same grade of staining by both methods, 14 had a higher grade with rubeanic acid, and only seven had a higher grade with rhodanine. However, small amounts of copper could more easily be distinguished from other 
Table 3 Grades of staining for copper and copperassociated protein in 17 patients with Wilson's disease, ranked in order of increasing liver copper concentration

\begin{tabular}{llll}
\hline Liver Cu (mmollkg) & Orcein & Rubeanic acid & Rhodanine \\
\hline 1.90 & 2 & 2 & 1 \\
2.63 & 0 & 0 & 0 \\
3.12 & 0 & 0 & 0 \\
4.69 & 1 & 0 & 0 \\
5.29 & 0 & 1 & 0 \\
5.57 & 0 & 0 & 0 \\
5.73 & 0 & 0 & 1 \\
6.14 & 2 & 2 & 3 \\
6.94 & 0 & 0 & 0 \\
8.69 & 3 & 3 & 3 \\
9.12 & 1 & 1 & 0 \\
9.70 & 0 & 0 & 0 \\
11.15 & 0 & 0 & 1 \\
12.49 & 0 & 0 & 1 \\
15.43 & 1 & 1 & 1 \\
15.84 & 0 & 0 & 1 \\
22.52 & 0 & 0 & 1 \\
\hline
\end{tabular}

materials such as bile and haemosiderin when stained with the orange-red rhodanine dye. The dull greenish-black colour of rubeanic acid tended to mimic other intracellular pigments by making positive identification of copper more difficult.

Thirty-three of the 35 PBC biopsy specimens stained for copper-associated protein with orcein, and in two of these the liver copper concentration was normal. Staining for copper-associated protein was more frequently and more strongly positive than staining for copper itself (Fig. 5).

\section{WILSON'S DISEASE}

There was no relation between the liver copper concentration measured by NAA, which was high in all cases, and the grade of staining for copper. Six of the 17 patients had positive staining for rubeanic acid, and nine were positive with rhodanine (Table 3). Only one patient, with a liver copper concentration of $8.69 \mathrm{mmol} / \mathrm{kg}$ dry liver, had grade 3 staining for copper by both methods, this being the only patient in the group with grade 3 orcein staining. Two patients had grade 2 , and three had grade 1 orcein staining for copper-associated protein, therefore six of the 17 were positive. Positive orcein and copper staining was not associated with histological or biochemical cholestasis, or with serum caeruloplasmin levels

\section{CHRONIC ACTIVE HEPATITIS}

Liver copper concentrations were above normal in five out of eight patients with $\mathrm{HB}_{\mathrm{s}} \mathrm{Ag}$ negative $\mathrm{CAH}$, mean 1.45 , range $0.45-2.88 \mathrm{mmol} / \mathrm{kg}$ dry liver. They were also elevated in five of the eight patients with $\mathrm{HB}_{\mathrm{s}} \mathrm{Ag}$ positive $\mathrm{CAH}$, mean $2 \cdot 15$, range 0.38-4.69 mmol/ $\mathrm{kg}$ (Table 4). Staining with rubeanic acid and rhodanine did not always detect

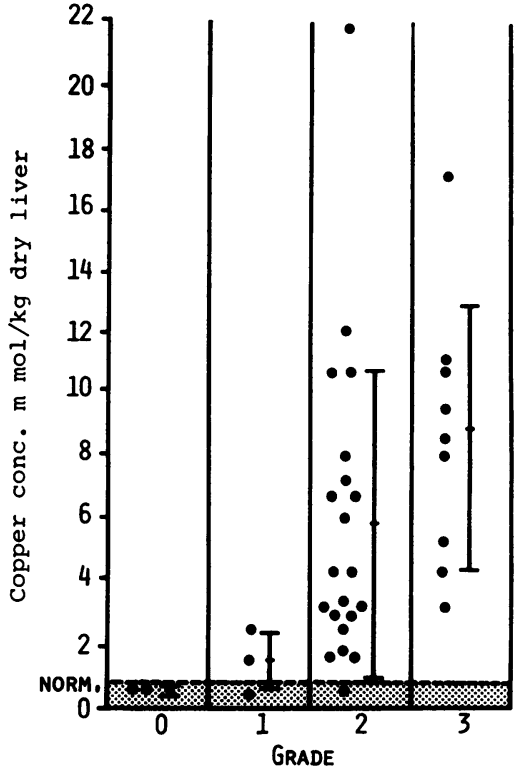

Fig. 5 Grade of staining for copper-associated protein by orcein in PBC, compared with copper concentration in mmol/kg dry liver. Mean and $S D$ are shown.

elevated liver copper, this being above normal in four out of nine patients with negative staining by both techniques. However, there was some agreement between grades of copper staining and the presence of orcein-positive copper-associated protein. Eleven of the $16 \mathrm{CAH}$ biopsies were of the same grade by all three staining methods.

Table 4 Grades of staining for copper and copper-associated protein in 16 patients with $\mathrm{CAH}$, $H_{B}$ Ag negative and positive, ranked in order of increasing liver copper concentration

\begin{tabular}{|c|c|c|c|c|}
\hline & $\begin{array}{l}\text { Liver Cu } \\
(\mathrm{mmol} / \mathrm{kg})\end{array}$ & Orcein & Rubeanic acid & Rhodanine \\
\hline & $\begin{array}{l}0.49 \\
0.69 \\
0.79\end{array}$ & $\begin{array}{l}0 \\
0 \\
2\end{array}$ & $\begin{array}{l}0 \\
0 \\
2\end{array}$ & $\begin{array}{l}0 \\
0 \\
1\end{array}$ \\
\hline $\begin{array}{l}\mathrm{HB}_{\mathrm{g}} \mathrm{Ag} \text { neg } \\
\mathrm{CAH}\end{array}$ & $\begin{array}{c}\ldots .98 \\
1.86 \\
1.89 \\
2.05 \\
2.88\end{array}$ & $\begin{array}{l}2 \\
0 \\
2 \\
1 \\
1\end{array}$ & $\begin{array}{l}2 \\
1 \\
2 \\
0 \\
1\end{array}$ & $\begin{array}{l}2 \\
1 \\
2 \\
0 \\
1\end{array}$ \\
\hline & $\begin{array}{l}0.38 \\
0.52 \\
0.85\end{array}$ & $\begin{array}{l}0 \\
0 \\
0\end{array}$ & $\begin{array}{l}\mathbf{0} \\
\mathbf{0} \\
\mathbf{0}\end{array}$ & $\begin{array}{l}0 \\
0 \\
0\end{array}$ \\
\hline $\begin{array}{l}\mathrm{HB}_{\mathbf{B}} \mathrm{Ag} \text { pos } \\
\mathrm{CAH}\end{array}$ & $\begin{array}{l}1.79 \\
1.92 \\
3.49 \\
3.54 \\
4.69\end{array}$ & $\begin{array}{l}2 \\
0 \\
0 \\
1 \\
0\end{array}$ & $\begin{array}{l}1 \\
0 \\
0 \\
2 \\
0\end{array}$ & $\begin{array}{l}2 \\
0 \\
0 \\
2 \\
0\end{array}$ \\
\hline
\end{tabular}




\section{Discussion}

Liver copper concentration can be measured on percutaneous biopsy specimens by NAA or atomic absorption spectrophotometry, but these techniques are not generally available, and as the biopsy must be taken with a needle washed in EDTA, the decision to measure the liver copper concentration must precede performance of the biopsy. Measurement of liver copper concentration is important in the diagnosis and treatment of Wilson's disease (Sternlieb and Scheinberg, 1968). Copper accumulation may perpetuate liver damage in PBC, so liver copper concentrations have been measured in trials of D-penicillamine treatment, which have found that the drug improves serum liver function tests (Jain et al., 1977) and may improve survival (Dickson et al., 1977).

Direct staining of liver sections in $\mathrm{PBC}$ was useful in discriminating between normal and elevated liver copper but did not give a reliable indication of the liver copper concentration. However, strongly positive (grade 3) staining was associated only with copper levels above $3.23 \mathrm{mmol} / \mathrm{kg}$ and may therefore influence the decision to use chelation therapy. The rubeanic acid stain gave better correlation with the liver copper concentration, but the dull colour of rubeanic acid was not so easily discernible as the orange-red of rhodanine, making the latter more suitable for routine use. Irons et al. (1977) came to a similar conclusion when several different staining methods for copper were applied to normal fetal, neonatal, and adult livers, and a small number of abnormal livers. Staining of the copper-associated protein in PBC by the orcein method was possibly too sensitive an index of copper accumulation as positive staining was found in 33 of 35 patients, two of whom had normal liver copper by NAA. However, in comparing NAA results with those of staining methods, it should be remembered that different samples of the same biopsy specimen were being examined.

In Wilson's disease, direct staining for copper was found to be of very limited use, as only six of 17 biopsy specimens were positive with rubeanic acid and nine of 17 were positive with rhodanine. Therefore, if this diagnosis is suspected the liver copper concentration should be measured, and a suitably prepared biopsy needle used. In contrast to PBC, sections from only six of the 17 patients with Wilson's disease stained with orcein, and these included five of the six which stained for copper by rubeanic acid. The accumulation of liver copper in PBC is therefore histochemically distinct from that of the majority of patients with Wilson's disease. In most of the specimens from patients with Wilson's disease, excess copper was usually demonstrable histologically only when orcein-positive copperassociated protein was also present. This strongly suggests that copper can be retained in the liver in different chemical forms. In PBC and the minority of patients with Wilson's disease a copper-associated protein is present; in most patients with Wilson's disease this protein is not demonstrable. The orcein-positive protein could be metallothionein as this contains many sulphydryl groups (Evans, 1971). Production of an abnormal metal-binding protein in Wilson's disease has been suggested but not confirmed (Evans et al., 1973).

Our findings of positive staining for copper by rubeanic acid in only six of 17 patients with Wilson's disease, though similar to those of Dastur and Manghani (1967), were in contrast to those of Goldfischer and Sternlieb (1968), who found positive staining by a similar technique in 14 of their 16 cases. However, the mean liver concentration in their patients was 1.6 times higher than those reported here.

In both types of CAH, orcein staining corresponded well with copper staining, but none of the stains gave a reliable guide to the liver copper concentration, which was frequently elevated when staining was negative. This suggests that, as in Wilson's disease, rubeanic acid and rhodanine can stain only copper, that is associated with proteins with sulphydryl groups, but that excess copper can also be present in another form.

Sipponen et al. (1975) found positive orcein staining in $20 \%$ of CAH patients, and $83 \%$ in PBC. They suggested that the presence of a copperbinding protein might be used for differential diagnosis. We have found positive orcein staining in five of eight patients $(62.5 \%)$ with $\mathrm{HB}_{\mathrm{s}} \mathrm{Ag}$ negative $\mathrm{CAH}$, and in 33 of $35(94.3 \%)$ with PBC, and do not therefore consider that the stain can distinguish reliably between the two diseases. However, grade 3 copper staining was not seen in any of the biopsy specimens from patients with CAH.

In CAH the liver copper concentration is usually below $4.0 \mathrm{mmol} / \mathrm{kg}$, and copper accumulation probably does not present a clinical problem.

We thank the Medical Research Council, the Wellcome Trust, and $\mathrm{Mr}$ Chester Beatty for financial support, and $\mathrm{Mr}$ Michael Nagle for helpful assistance.

\section{References}

Cartwright, G. E., and Wintrobe, M. M. (1964). Copper 
metabolism in normal subjects. Americal Journal of Clinical Nutrition, 14, 224-232.

Cook, H. C. (1974). Manual of Histological Demonstration Techniques, pp. 237-238, Butterworths, London.

Cumings, J. N. (1948). The copper and iron content of brain and liver in the normal and in hepato-lenticular degeneration. Brain, 71, 410-415.

Dastur, D. K., and Manghani, D. K. (1967). The liver in Wilson's disease. Some histochemical and histological aspects. Indian Journal of Pathology and Bacteriology, 10, 177-183.

Deodhar, K. P., Tapp, E., and Scheuer, P. J. (1975). Orcein staining of hepatitis $\mathbf{B}$ antigen in paraffin section of liver biopsies. Journal of Clinical Pathology, 28, 66-70.

Dickson, E. R., Fleming, C. R., Geall, M. G., McCall, J. T., and Baggenstoss, A. H. (1977). A double-blind controlled study using D-penicillamine in chronic cholangiolotic hepatitis (primary biliary cirrhosis). (Abstract.) Gastroenterology, 72, 1049.

Evans, G. W. (1971). Function and nomenclature for two mammalian copper proteins. Nutrition Reviews, 29, 195-197.

Evans, G. W., Dubois, R. S., and Hambidge, K. M. (1973). Wilson's disease: identification of an abnormal copper-binding protein. Science, 181, 1175-1176.

Fleming, C. R., Dickson, E. R., Baggenstoss, A. H., and McCall, J. T. (1974). Copper and primary biliary cirrhosis. Gastroenterology, 67, 1182-1187.

Goldfischer, S., and Sternlieb, I. (1968). Changes in the distribution of hepatic copper in relation to the progression of Wilson's disease (hepatolenticular degeneration). American Journal of Pathology, 53, 883-901.

Howell, J. S. (1959). Histochemical demonstration of copper in copper-fed rats and in hepatolenticular degeneration. Journal of Pathology and Bacteriology, 77, 473-484.

Hunt, A. H., Parr, R. M., Taylor, D. M., and Trott, N. G. (1963). Relation between cirrhosis and trace metal content of liver. British Medical Journal, 2, 1498-1501.

Irons, R. D., Schenk, E. A., and Lee, J. C. K. (1977). Cytochemical methods for copper. Archives of Pathology and Laboratory Medicine, 101, 298-301.

Jain, S., Scheuer, P. J., Samourain, S., McGee, J. O’D., and Sherlock, S. (1977). A controlled trial of d-penicillamine therapy in primary biliary cirrhosis. Lancet, 1, 831-834.

Lindquist, R. R. (1969). Studies on the pathogenesis of hepato lenticular degeneration. II. Cytochemical methods for the localisation of copper. Archives of Pathology, 87, 370-379.

Mallory, F. B., and Parker, F., Jr. (1939). Fixing and staining methods for lead and copper in tissues. American Journal of Pathology, 15, 517-522.

Salaspuro, M., and Sipponen, P. (1976). Demonstration of an intracellular copper-binding protein by orcein staining in long-standing cholestatic liver diseases. Gut, 17, 787-790.

Scheuer, P. J., and Barka, T. (1963). Extraction of copper from sections as tested with a radioisotope. Journal of Histochemistry and Cytochemistry, 11, 814-815.

Shikata, T., Uzawa, T., Yoshiwara, N., Akatsuka, T., and Yamazaki, S. (1974). Staining methods of Australia antigen in paraffin section. Japanese Journal of Experimental Medicine, 44, 25-36.

Sipponen, P. (1976). Orcein positive hepatocellular material in long-standing biliary diseases. I. Histochemical characteristics. Scandinavian Journal of Gastroenterology, 11, 545-552.

Sipponen, P., Salaspuro, M. P., and Makkonen, H. M. (1975). Orcein positive hepatocellular material in histological diagnosis of primary biliary cirrhosis. Annals of Clinical Research, 7, 273-277.

Smallwood, R. A., Williams, H. A., Rosenoer, V. M., and Sherlock, S. (1968). Liver-copper levels in liver disease. Lancet, 2, 1310-1313.

Sternlieb, I. (1972). Evolution of the hepatic lesion in Wilson's disease (hepatolenticular degeneration). Progress in Liver Diseases, 4, 511-525.

Sternlieb, I., and Scheinberg, I. H. (1968). Prevention of Wilson's disease in asymptomatic patients. New England Journal of Medicine, 278, 352-359.

Todd, A. P., Thorpe, M. E. C., and Rosenoer, V. M. (1967). Tissue copper determinations by neutron activation analysis. Journal of Clinical Pathology, 20, 276-279.

Requests for reprints to: Dr S. Jain, The Royal Free Hospital, Pond Street, Hampstead, London NW3 3QG, UK. 